\title{
HOUSE OF BLACK SOLDIER FLIES PETERNAKAN DAN GALERI EKOSISTEM LALAT TENTARA HITAM
}

\author{
Mikael Morgan ${ }^{1)}$, Alvin Hadiwono ${ }^{21}$ \\ 1)Program Studi S1 Arsitektur, Fakultas Teknik, Universitas Tarumanagara, mikaelmorgan99@gmail.com \\ 2) Program Studi S1 Arsitektur, Fakultas Teknik, Universitas Tarumanagara, alvinh@ft.untar.ac.id
}

\begin{abstract}
Abstrak
Tempat Pembuangan Sampah Terpadu (TPST) Bantar Gebang merupakan TPST terbesar se-Asia. Ekosistem yang unik lahir dari jutaan sampah yang meliputi gunungan sampah organik anorganik, ribuan pemulung, serta jutaan lalat. Akan tetapi, ekosistem di TPST ini belum bekerja dengan baik, antar komponen dalam ekosistem masih bekerja sendirisendiri dan tidak bekerja secara mutualisme. Program hadir dalam tujuan memaksimalkan ekosistem yang ada di TPST ini, dengan menjadikan antar komponen sebagai satu kesatuan. Seperti program peternakan lalat BSF yang berbahan dasar sampah organik, workshop sampah bagi para pemulung, dan galeri informasi mengenai lalat dan sampah bagi masyarakat luar. Mengolah sampah organik secara alami (menggunakan lalat BSF), maka program ini menjadi sangat ramah lingkungan dan ekologis. Metode perancangan seperti keberlanjutan dan biomimikri dipakai untuk menghasilkan proyek yang peduli terhadap lingkungan, serta menargetkan pada tingkat psikologis masyarakat. Dengan begitu, proyek diharapkan dapat membantu mengatasi masalah sampah organik di TPST Bantar Gebang, serta membuka wawasan masyarakat luas tentang pengolahan sampah.
\end{abstract}

Kata kunci: lalat; pemulung; pengolahan; sampah TPST Bantar Gebang.

\begin{abstract}
The Bantar Gebang Integrated Waste Disposal Site (Bantar Gebang Landfill) is the largest landfill in Asia. This unique ecosystem is born from millions of garbage which include mountains of inorganic and organic waste, thousands of scavengers, and millions of flies. However, the ecosystem in this landfill has not worked well, the components in the ecosystem still work independently and do not work in mutualism way. The program is present with the aim of maximizing the existing ecosystem in this landfill, by making the components as one unit. Such as the Black Soldier flies breeding program which is made from organic waste, a waste workshop for the scavengers, and an information gallery about flies and garbage for the outside people. Processing organic waste naturally (using Black Soldier flies), make this program is very environmentally and ecologically friendly. Design methods such as sustainability and biomimicry are used to produce projects that care about the environment, and target the psychological level of the people. By doing so, the project is expected to be able to help overcome the problem of organic waste in the Bantar Gebang Landfill, as well as open up public knowledge about waste management.
\end{abstract}

Keywords: Bantar Gebang Landfill; disposal; flies, scavengers; waste.

\section{PENDAHULUAN}

\section{Latar Belakang}

Sampah merupakan salah satu masalah yang sangat besar saat ini. Masalah ini muncul akibat ketidakmampuan manusia untuk mendaur ulang atau mengolah sampah yang dihasilkan oleh manusia itu sendiri. Sehingga sampah yang tidak terolah ini menjadi polusi bagi lingkungan sekitar dan bagi bumi ini. Saat ini Indonesia merupakan negara dengan peringkat ke-2 sebagai penyumbang sampah di dunia. 
TPST Bantar Gebang yang berlokasi di Bekasi ini merupakan TPST terbesar se-Asia dimana di TPST ini, sampah masih diolah dengan sistem open dumping, yaitu sampah dibiarkan di lahan terbuka. TPST Bantar Gebang dikatakan akan penuh pada tahun 2022. Selain itu, pemerintah sudah menerapkan beberapa cara dalam mengolah sampah, seperti mengubur sampah dan dijadikan gas metana, pengolahan sampah plastik, dan sebagainya. Akan tetapi, pengolahan ini masih sangat minim, dan belum dapat menyelesaikan permasalahan sampah di TPST ini.

Sampah organik menjadi sampah dengan volume terbesar di TPST ini (sekitar 60\%). Pengolahan sampah organik yang sudah dilakukan oleh pemerintah adalah menimbunnya, dan sebagian dijadikan kompos. Tentunya hal ini masih belum dapat mengatasi permasalahan volume sampah organik yang terus menumpuk. Salah satu cara pengolahan sampah organik yang sangat ramah lingkungan adalah dengan menggunakan atau mengikuti cara yang sudah ada pada alaminya. Yaitu dengan menggunakan lalat sebagai pengurai alami. Jenis lalat tentara hitam atau lalat BSF, berbeda dengan jenis lalat lainnya. Jenis lalat ini tidak membawa penyakit, sehingga larva atau maggot dari lalat ini sangat bagus untuk dikonsumsi terutama bagi hewan ternak seperti unggas, ikan dan lainnya. Larva dari lalat ini juga dapat mengurai sampah organik dalam jumlah yang besar, sehingga pengolahan sampah dengan lalat ini menjadi sangat ekologis, serta ramah lingkungan.

\section{Rumusan Masalah}

Pemilihan isu merupakan hasil dari pertimbangan berbagai aspek permasalahan, antara lain:

- Permasalahan global yang dihadapi dunia saat ini terutama Indonesia.

- Permasalahan yang sangat dekat dengan kehidupan sehari-hari kita manusia.

- Berdampak pada lingkungan dalam skala yang luas dan jangka waktu yang panjang.

- TPST Bantar Gebang merupakan TPST / TPA terbesar se-Asia bahkan sedunia

- Munculnya ekosistem yang unik antara sampah, lalat, dan para pemulung.

Beberapa permasalahan yang dihadapi antara lain adalah:

1. Permasalahan Umum:

- Bagaimana lingkungan sampah dapat menjadi ekosistem bagi para pemulung di TPST Bantar Gebang?

- Bagaimana ekosistem atau lingkungan hidup yang terjadi di TPST Bantar Gebang?

2. Permasalahan Khusus Pengamatan TPST Bantar Gebang:

- Bagaimana proyek dapat membantu mengoptimalkan pengolahan sampah yang ada di TPST Bantar Gebang?

- Bagaimana cara memanfaatkan ekosistem yang sudah ada untuk mengoptimalkan pengolahan sampah di TPST Bantar Gebang?

Lingkup penulisan ini adalah membuka paradigma baru tentang sampah terutama untuk masyarakat sekitar yang berpikiran bahwa sampah itu adalah barang tidak berguna. Maka diharapkan dengan studi dan kajian ini masyarakat dapat menghargai serta menemukan nilainilai positif yang ada dalam sampah yang setiap hari dihasilkan oleh manusia, serta meningkatkan kesadaran akan pentingnya masalah sampah di lingkungan sekitar.

Proyek ini bertujuan untuk mengoptimalkan pengolahan sampah yang ada di TPST Bantar Gebang dengan memanfaatkan ekosistem yang sudah ada. Selain itu juga membuka pandangan ke masyarakat sekitar tentang nilai positif dari sampah dan memberikan wawasan tentang sampah organik anorganik serta cara mengolah sampah secara mandiri. Proyek juga bertujuan untuk meningkatkan kualitas hidup para pemulung sekitar TPST dan sebagai wisata bagi masyarakat sekitar. 


\section{KAJIAN LITERATUR}

\section{Pengertian Ekologi, Ekosistem dan Beyond Ecology}

Ekologi dan ekosistem sendiri memiliki pengertian yang sangat luas, sehingga banyak buku yang menulis tentang ekologi dengan pandangan yang berbeda-beda. Seperti dalam buku Deep Ecology (Devall B, 1985), bahwa setiap benda, makhluk hidup dan apa pun itu, memiliki nilai intrinsiknya masing-masing. Manusia zaman sekarang memandang segala hal dengan cara yang mekanistik, seperti kita melihat panas, awan, dan langit sebagian komponen yang berbeda. Manusia zaman dulu atau mungkin hewan melihat ini sebagai suatu kesatuan. Manusia menjalankan mesin, atau mesin yang menjalankan manusia, karena manusia membutuhkan mesin, menjalankannya, dan juga merawatnya. Berbeda dengan buku Cradle to Cradle. Dulu konsep berprinsip "from cradle to grave" ini digunakan oleh manusia dalam pengelolaan limbah dan sampah. Tiga solusi umum yang digunakan oleh perusahaan saat ini sesuai paradigma cradle to grave adalah pertama, daur ulang. Kedua downcycling, mengubah produk menjadi berkualitas rendah. Ketiga upcycling, mengubah suatu produk menjadi lebih unggul. Selain dari era cradle to grave, sekarang ini juga banyak berkembang prinsip cradle to cradle, dimana visi dari pengelolaan ini adalah membuat atau memproduksi apa pun itu, tanpa menghasilkan limbah atau sampah. Terdapat tiga prinsip atau paradigma dalam cradle to cradle. Pertama menghilangkan konsep sampah. Kedua menggunakan energi terbarukan. Ketiga menghargai keanekaragaman ekosistem.

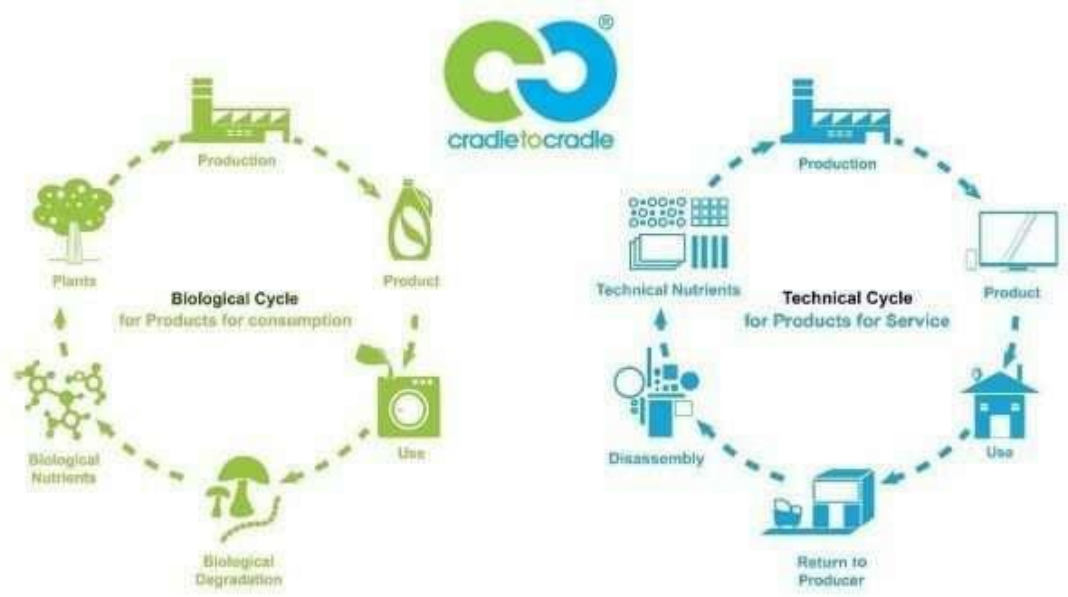

Gambar 1. Prinsip siklus Cradle to Cradle

Sumber:

Beyond Ecology, dalam pengertian bahasa Indonesianya adalah melampaui ekologi. Dimana dalam pandangan para ahli serta buku, pengertian melampui ekologi ini berbeda-beda. Beberapa kategori beyond ecology (Sutanto, 2020) adalah energy and emission, adaptation architecture, resilience architecture, sustainable digital architecture, new technology dan context. Energy and emission adalah pengolahan energi dengan meminimalkan emisi yang dihasilkan, dapat berupa penggunaan material atau organisasi ruang. Adaptation architecture adalah penelitian yang dilakukan terhadap lingkungan sekitar, seperti iklim dan lainnya. Resilience architecture adalah bagaimana ketahanan bangunan terhadap masalah yang akan muncul kedepannya. Sustainable digital architecture adalah pengolahan data terhadap lingkungan sekitar tapak untuk dipakai dalam pengolahan ruang. New Technology adalah memakai teknologi baru pada proyek, seperti material, dan lainnya. Context adalah nilai kontekstual proyek terhadap lingkungan sekitarnya. 


\section{Sampah}

Menurut UU Republik Indonesia Nomor 18 Tahun 2008 tentang Pengelolaan Sampah, sampah adalah sisa kegiatan sehari-hari manusia dan atau proses alam yang berbentuk padat (Depkes RI, 2008). Sampah sudah menjadi persoalan dunia, dimana dalam ekosistem, jumlah sampah melebihi kapasitas dari komponen ekosistem lainnya, sehingga membuat ketidakseimbangan ekosistem dan mengakibatkan pada masalah atau bencana lainnya. Indonesia menempati urutan ke-2 dalam kontribusi terhadap sampah di dunia. Dari data Kementerian Lingkungan Hidup dan Kehutanan (KLHK) pada Februari 2019, sampah di Indonesia mencapai 64 juta ton setiap tahunnya. Sebanyak 60 persen dari sampah tersebut ditimbun di TPA, 10 persen didaur ulang, dan 30 persen tidak dikelola. Dari seluruh sampah tersebut, sampah organik mencapai 60 persen, sampah plastik 14 persen, sampah kertas 9 persen, dan karet 5.5 persen.

\section{TPST Bantar Gebang}

Bantar Gebang merupakan kecamatan di Kota Bekasi, Jawa Barat, Indonesia. Tempat Pembuangan Akhir (TPA) adalah tempat sampah-sampah dikumpulkan yang diatur oleh pemerintah. TPA Bantar Gebang yang sekarang disebut Tempat Pengolahan Sampah Terpadu (TPST) di Bantar Gebang Bekasi ini menjadi TPST terbesar di Indonesia, bahkan di dunia dilansir dari National Geographic. Sampah di TPST ini berasal dari sampah DKI Jakarta, dan Kepulauan Seribu. Sampah dari Jakarta sendiri mencapai kurang lebih 8.700 ton per hari, sedangkan dari Kepulauan Seribu sekitar 770 ton per hari. Sekitar 1.200 truk sampah beroperasi setiap harinya. Luas lahan TPST Bantar Gebang adalah sekitar $113 \mathrm{Ha}$, yang terdiri dari landfill 81,40 Ha dan sarana prasarana 23,30 Ha. Di TPST Bantar Gebang ini memiliki ekosistem yang unik dengan komponen antara lain, mencapai 6000 pemulung, jutaan sampah, dan jutaan lalat. Sampah menjadi mata pencaharian utama bagi para pemulung ini. Sampah-sampah di TPST ini sudah ada pengolahannya oleh pihak TPST. Seperti pemilahan antara sampah organik dan anorganik, kemudian sampah organik akan dijadikan kompos, dan sampah anorganik seperti plastik dijadikan bahan dasar Pembangkit Listrik Tenaga Sampah (PLTSA).

\section{Peternakan Lalat Tentara Hitam}

Siklus hidup lalat BSF dari telur menjadi dewasa sekitar 40-43 hari. Suhu menjadi salah satu faktor penting dalam siklus hidup lalat BSF ini. Suhu $30^{\circ} \mathrm{C}$ adalah suhu yang optimal untuk larva dapat tumbuh dan berkembang menjadi larva yang yang lebih aktif dan produktif, suhu juga berpengaruh terhadap masa inkubasi telur. Pada suhu $36^{\circ} \mathrm{C}$ tidak dapat bertahan hidup dan tidak dapat berkembang biak karena terlalu panas, pada suhu $27^{\circ} \mathrm{C}$ larva atau prepupa akan mengalama perkembangan empat hari lebih lambat dibandingkan pada suhu $30^{\circ} \mathrm{C}$ (Tumberlin, Adler, \& Myers, 2009). Lalat betina BSF akan bertelur di sekitar sumber makanan seperti pada tumpukan limbah bungkul inti sawit, bongkahan kotoran hewan dan ternak. Tetapi lalat jenis BSF ini tidak bertelur secara langsung di atas sumber pakan seperti lalat lainnya. Lalat BSF akan bertelur di sekitar pakan pada tempat yang bersih, seperti di daun pisang atau potongan kardus di atas media pakan. Lalat betina dapat memproduksi 185-1235 telur dalam satu siklusnya. Dalam data literatur lain, lalat betina membutuhkan waktu 20-30 menit untuk bertelur dengan memproduksi telur sebanyak 546-1.505 butir dan berat massa telur $16 \mathrm{mg}$ dengan berat individu masing-masing sekitar 0,026-0,030 mg (Santi, \& Mahmud, A. T., 2019).

Peternakan lalat jenis ini sangat mudah, hal yang perlu disiapkan adalah kandang tempat lalat dewasa tinggal, wadah tempat larva BSF tumbuh, dan tempat pengelolaan telur BSF. Secara pengelolaannya, larva atau maggot BSF akan diletakkan di wadah yang sudah berisi sampah organik. Maggot BSF akan makan dan tumbuh di wadah tersebut hingga menjadi pupa. Maggot yang sebelum menjadi pupa dapat diambil dan dijadikan pakan ternak unggas atau ikan. Lalu pupa yang sudah dipisahkan akan dibiarkan untuk menjadi lalat dewasa dan menghasilkan 
telur-telur BSF. Seterusnya siklus ini bekerja secara berulang. Hal yang perlu diperhatikan adalah kandang lalat dewasa membutuhkan panas matahari yang cukup dan tempat tinggal seperti pohon atau daun-daun, serta sirkulasi udara yang cukup (suhu sekitar $35^{\circ} \mathrm{C}$ adalah suhu yang optimal untuk lalat dewasa agar produktif). Sedangkan lingkungan tempat maggot BSF tidak boleh terlalu panas agar maggot tidak mati (suhu ideal adalah $30^{\circ} \mathrm{C}$ ).
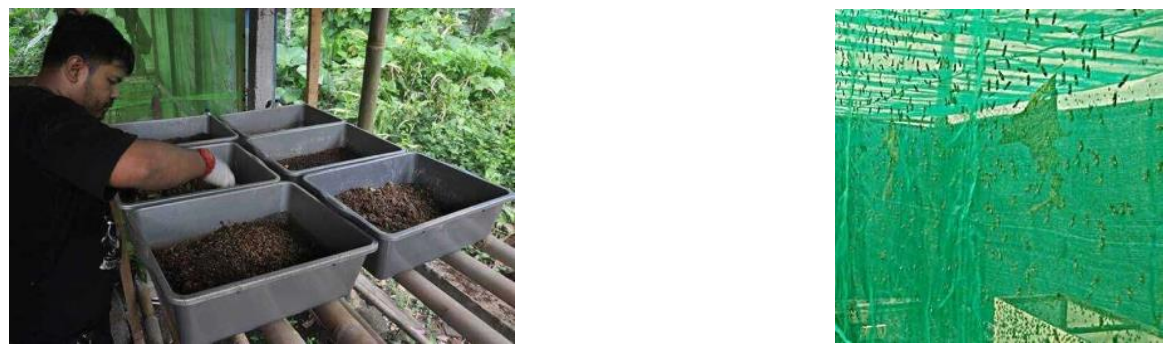

Gambar 2. Wadah Maggot BSF dan Kandang Lalat BSF

\section{METODE}

\section{Metode Perancangan}

Metode yang digunakan untuk pengumpulan data adalah studi preseden dan literatur. Studi preseden ini dikumpulkan dan dikomparasi sesuai dengan program pada proyek. Metode perancangan yang digunakan ada 3, yaitu biomimikri, eksperimental dan keberlanjutan (sustainable). Biomimikri digunakan pada program peternakan lalat BSF dan kandang lalat BSF. Peternakan lalat BSF meniru pada siklus kehidupan lalat BSF alaminya. Seperti makanan berupa sampah organik sebagai bahan pakan maggot BSF dan kandang yang ditutup kaca dengan pohon sebagai tempat tinggal lalatnya. Metode eksperimental digunakan pada program instalasi lalat, sehingga pengunjung dapat merasakan atau melihat sesuatu dari sudut pandang lalat. Keberlanjutan juga digunakan dalam desain proyek, seperti sistem rainharvesting, pengolahan sampah dengan lalat BSF, mendaur ulang sampah di workshop sampah, penggunaan sampah organik sebagai pupuk, dan sebagainya.

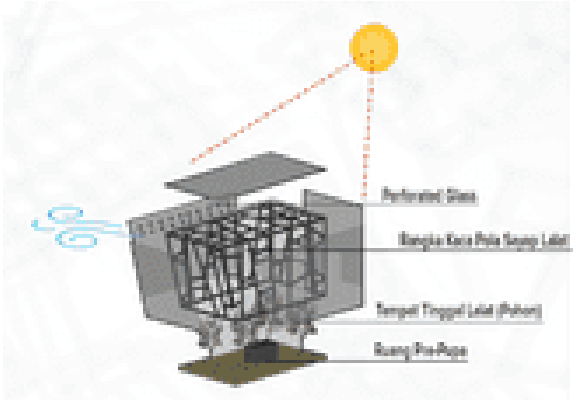

Gambar 3. Desain Kandang Lalat BSF

Beberapa studi preseden yang digunakan sebagai pengumpulan data dan menjadi acuan dalam desain serta program pada proyek:

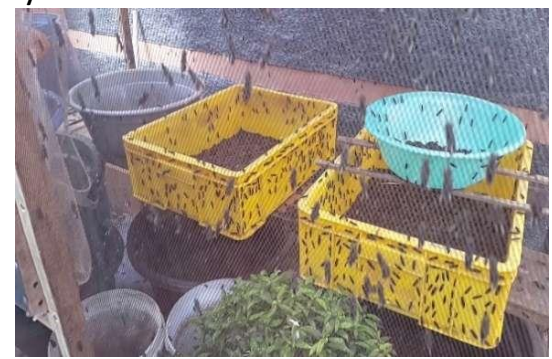

Gambar 4. Peternakan lalat BSF 
Peternakan lalat BSF dengan bahan dasar sampah organik. Maggot yang dihasilkan dapat menjadi bahan pakan unggas, ikan atau dijual sebagai maggot kering. Peternakan ini bersifat ramah lingkungan, karena cara beternaknya dan bahan yang dipakai sangat ramah lingkungan.

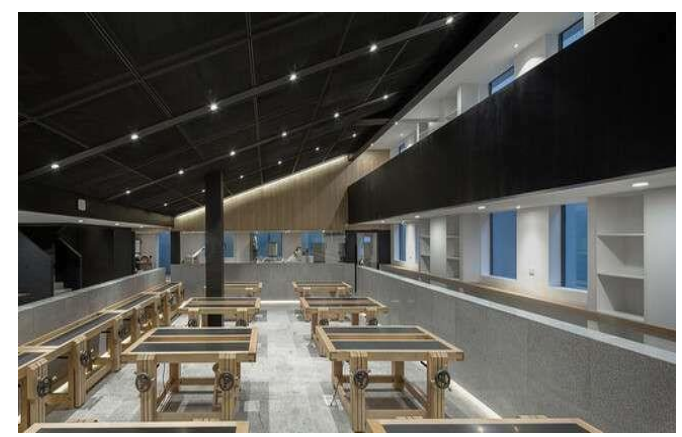

Gambar 5. M.Y.Lab Workshop

M.Y.Lab Workshop. Studio workshop berupa meja-meja yang dapat dipakai perorangan. Pencahayaan alami dan buatan yang cukup agar orang dapat bekerja dengan nyaman, selain itu juga tempat penyimpanan alat-alat, serta jarak antar ruang kerja yang ergonomis.

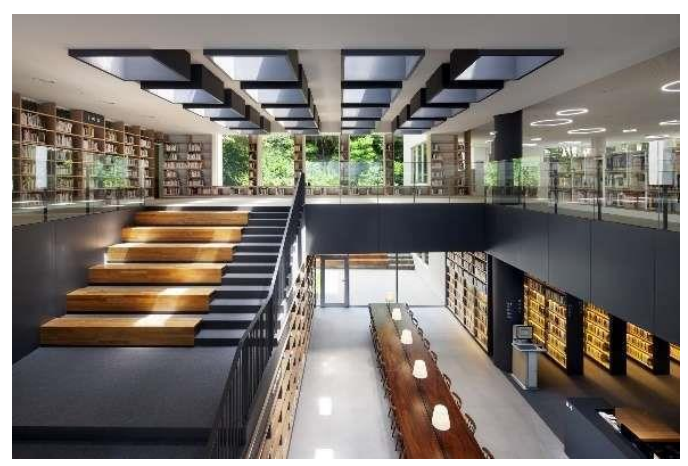

Gambar 6. Doksan Library

Desain perpustakaan dengan pemanfaatan seperti skylight, dan bukaan-bukaan yang besar sehingga pencahayaan alami dapat masuk, serta view juga didapat. Kenyamanan menjadi kunci utama dalam mendesain perpustakaan terutama dalam hal kenyamanan membaca. Peletakkan posisi rak buku terhadap area membaca juga harus berdekatan.

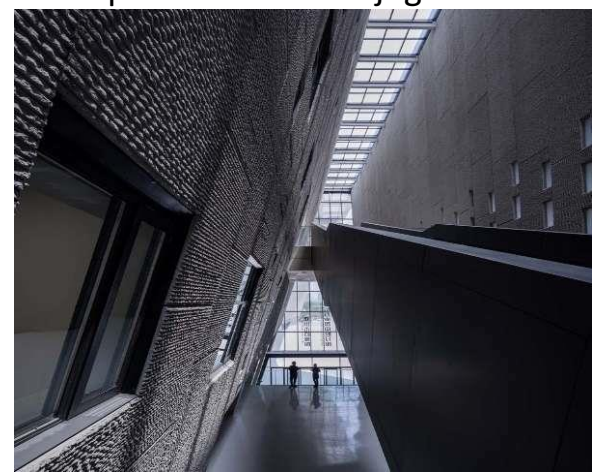

Gambar 7. Zhengzhou Art Museum

Zhenzhou Art Museum menampilkan barang barang seni dari Cina. Ruang-ruang yang didesain merespon terhadap benda yang dipamerkan. Seperti ruang yang bersifat tertutup (minim bukaan) agar benda yang dipamerkan menjadi lebih terfokus. Pencahayaan juga menjadi faktor penting untuk dapat lebih mengeluarkan ekspresi benda yang dipamerkan. 


\section{Analisis Program}

Program yang dihasilkan berdasarkan isu mencakup tiga hal. Pertama, program peternakan lalat BSF. Program ini bertujuan untuk mengurangi jumlah sampah organik dengan cara yang ekologis, serta hasil dari peternakan dapat dijual atau dijadikan bahan pakan unggas dan ikan. Sampah organik diambil dari TPST Bantar Gebang sehingga terjalin simbiosis mutualisme. Program kedua mentargetkan para pemulung sekitar. Dengan program workshop sampah dan perpustakaan, para pemulung dapat meningkatkan kualitas hidupnya dari segi ekonomi ataupun edukasi. Perpustakaan hadir untuk membantu edukasi terutama anak-anak pemulung sekitar yang berpendidikan rendah. Program ketiga adalah galeri seni, informasi sampah dan lalat. Program ini mentargetkan masyarakat luar dengan tujuan menambah wawasan tentang sampah dan lalat sehingga dapat menjadi modal usaha ataupun modal pengetahuan agar dapat mengolah sampah yang lebih efisien secara mandiri. Acuan program adalah peternakan BSF sebesar $40 \%$, galeri informasi dan instalasi sebesar $25 \%$, workshop dan perpustakaan sebesar $25 \%$, dan penunjang lainnya $10 \%$.

\section{Analisis Tapak}
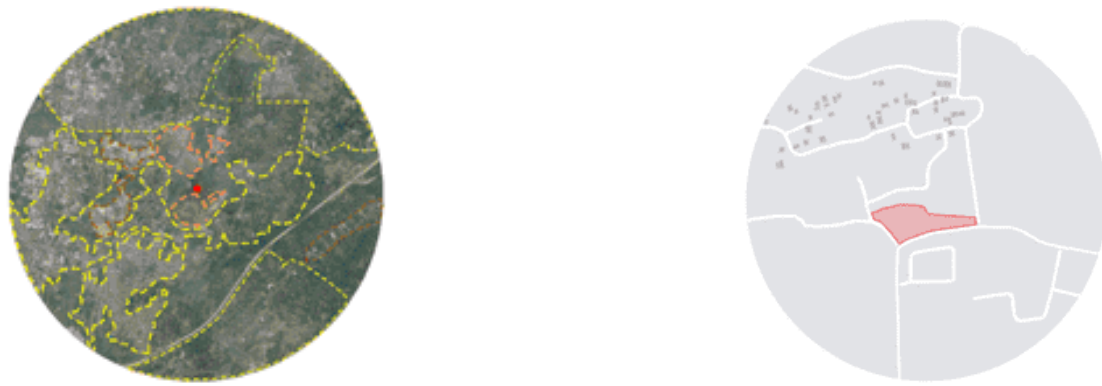

Gambar 8. Peta Kawasan Radius 3 km \& Peta Sekitar Tapak Sumber: Dokumen Pribadi, 2021

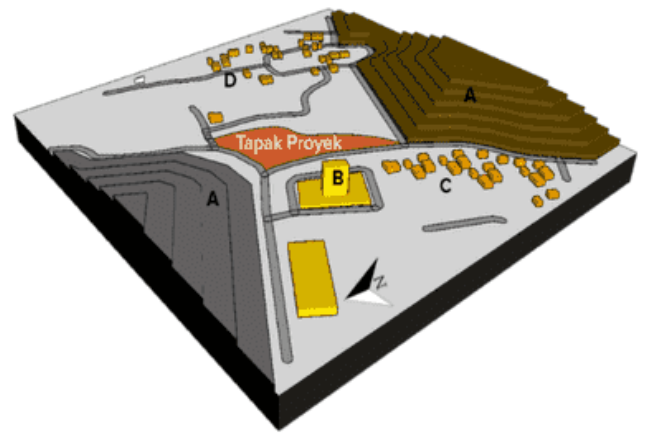

Gambar 9. 3D sekitar tapak Sumber: Dokumen Pribadi, 2021

Lokasi tapak berada di jalan Jalak Bali 3 RT.003, RW.005, Kecamatan Bantar Gebang, Kota Bekasi, Jakarta Barat. Wilayah sekitar belum ada Rencana Tata Ruang Wilayah (RTRW), sehingga menggunakan RTRW paling wilayah paling dekat serta melihat tata kota yang existing. Berdasarkan analisis, didapatkan KB 2, KDH 30\%, KLB 1.5, KDB 60\%.

Luas tapak sebesar $8225 \mathrm{~m} 2$. Dalam radius $3 \mathrm{~km}$, kawasan didominasi oleh permukiman warga (warna kuning), dengan beberapa area sebagai kawasan industri (warna cokelat), dan zona TPST Bantar Gebang (warna cream). Tapak pilihan (warna merah) berada di area Tempat Pengolahan Sampah Terpadu (TPST) Bantar Gebang. Lokasi dipilih berdasarkan tata kota sekitar, serta berdekatan dengan TPST untuk menjawab isu yang disampaikan. Lokasi pilihan tapak juga berdasarkan pada 3 target utama yaitu, TPST Bantar Gebang, para pemulung, dan tempat pemilahan sampah TPST). Area di sekitar tapak terdapat (A) zona gunungan sampah 
yang sudah di tutupi tanah untuk mengurangi bau, (B) Pembangkit Listrik Tenaga Sampah (PLTSA), (C) area pemilahan sampah organik anorganik, seperti plastik, sampah makanan, logam, dan lain-lain, (D) area perumahan warga sekitar permanen semi-permanen dengan ketinggian 1-2 lantai.

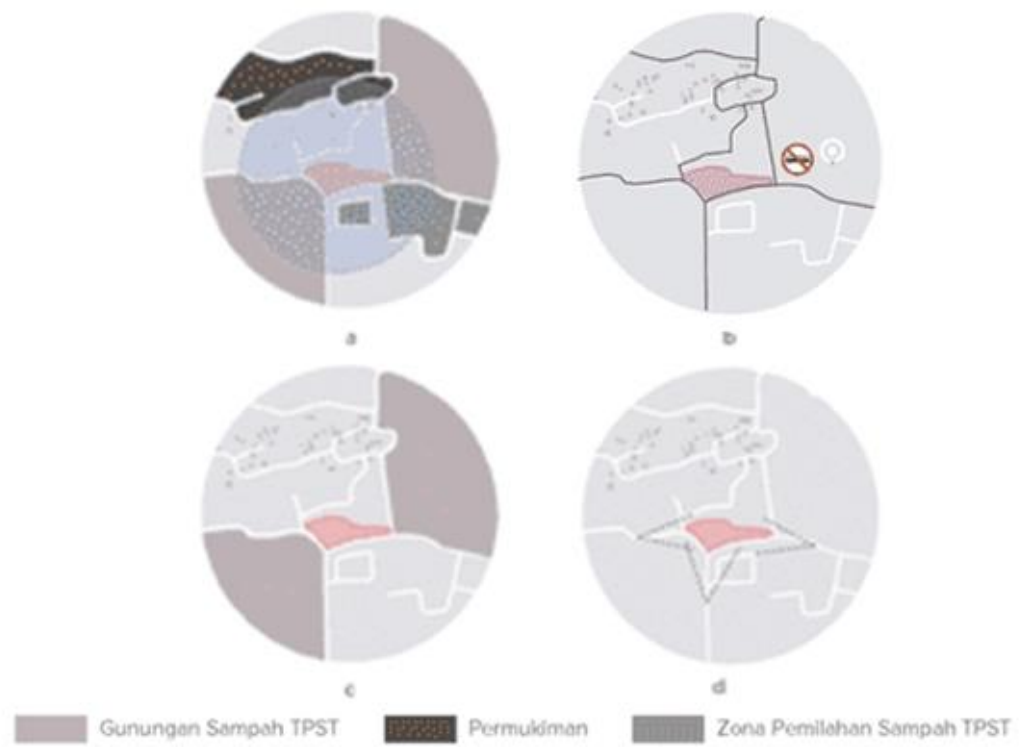

Gambar 10. Analisis tapak

Sumber: Dokumen Pribadi, 2021

Dalam radius 200 meter, lokasi pilihan tapak mencakup 3 target utama yaitu, zona pemilahan sampah TPST, warga sekitar (permukiman), dan zona gunungan sampah TPST. Akses menuju tapak mudah dilalui dan dijangkau. Jalan raya selebar 8 meter dengan 2 lajur dan 1 jalur. Semua jenis kendaraan dapat mengakses jalan raya ini (sepeda, motor, mobil, truk, bus, dan lain-lain). Dalam radius $1 \mathrm{~km}$, tidak ada transportasi umum seperti bus dan kereta. Transportasi umum yang tersedia adalah transportasi online. Gunungan sampah di sekitar tapak sudah tidak aktif dan sudah ditutupi dengan tanah merah sebagai upaya mengurangi bau sampah. Tapak memiliki 3 sumbu axis kawasan yang kuat dan juga bentuk tapak yang organik diambil berdasarkan bentuk kondisi eksisting yang sudah ada.

\section{DISKUSI DAN HASIL}

Dari hasil analisis dan literatur (Unimus, 2021), maggot atau larva lalat adalah makhluk pengurai. Makanannya adalah buah busuk, bangkai hewan dan lainnya. Proyek ini hadir untuk memaksimalkan ekosistem yang ada di TPST Bantar Gebang, dengan program berupa peternakan lalat BSF dan galeri informasi lalat dan sampah. Peternakan lalat BSF ini bertujuan untuk mengurangi jumlah sampah organik yang berlebihan di TPST, sedangkan galeri informasi bertujuan untuk membuka wawasan serta pandangan masyarakat terhadap pengolahan sampah dan lalat. Hasil rancangan dengan metode biomimikri dan keberlanjutan ini menghasilkan ekosistem yang ramah lingkungan, karena mengadaptasi atau meniru siklus alami yang sudah ada. Sampah-sampah organik akan diurai oleh maggot BSF, sehingga mengurangi jumlah sampah organik di TPST. Sebagian dari maggot tersebut akan dijadikan pakan ternak unggas atau ikan, sedangkan sebagiannya lagi akan dibiarkan menjadi lalat dewasa. Lalat BSF Dewasa ini akan diletakkan di kandang khusus, dan sesuai dengan kehidupan alaminya, lalat dewasa BSF hidup hanya untuk bereproduksi. Setelah bereproduksi, lalat BSF akan mati. Dengan cara beternak seperti ini, emisi yang dihasilkan akan sangat sedikit, dan tidak menghasilkan polusi. 


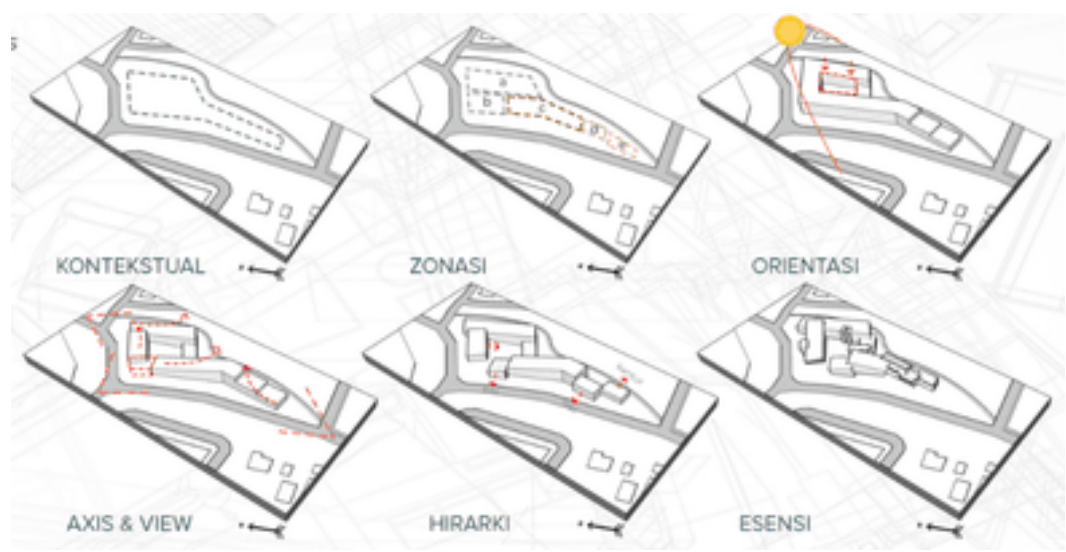

Gambar 11. Proses Desain

Sumber: Dokumen Pribadi, 2021

Proses desain gubahan massa mencakup poin kontekstual, dimana bentuk dasar massa konteks dengan bentuk tapak. Kemudian pembagian zonasi yang didasari oleh analisis tapak. Program peternakan yang sifatnya industri (a) diletakan di zona belakang tapak sedangkan program yang targetnya adalah masyarakat (b, c, d) diletakan di zona depan dekat entrance. Orientasi massa berpusat di tengah dan ke arah dalam. Hal ini berdasarkan tidak adanya daya tarik visual (bangunan ikonik, pemandangan, atau sebagainya) di sekitar tapak. Zona pada area tengah tersebut berupa ruang publik terbuka dan massa yang mengelilinginya berperan sebagai shading.

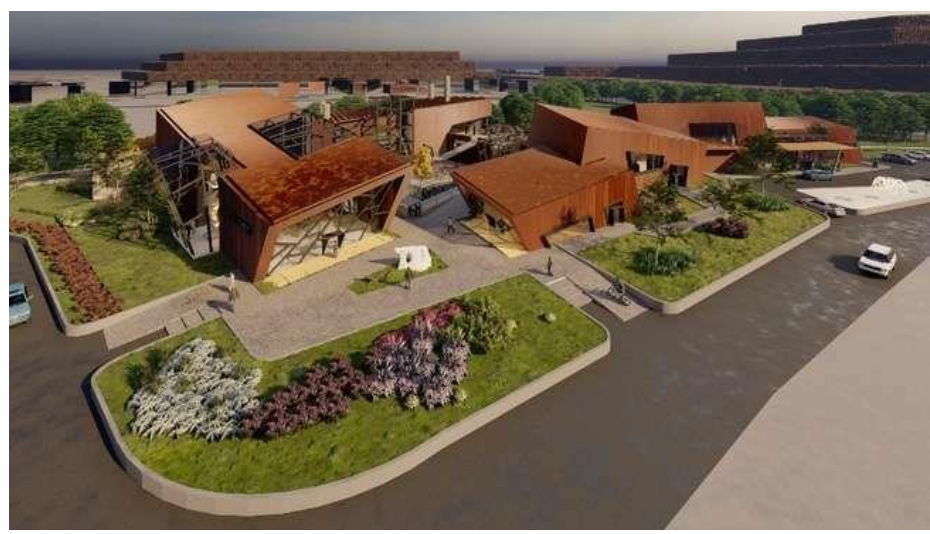

Gambar 12. Perspektif bird view

Sumber: Dokumen Pribadi, 2021

Aksen-aksen pada desain bangunan mengambil atau mengadaptasi dari morfologi lalat dan ekosistem lalat, seperti bentuk rangka jendela mengadaptasi dari pola saraf pada sayap lalat. Pemilihan pola besi berkarat sebagai fasad bangunan juga diambil agar kontekstual dengan lingkungan sampah. Selain itu juga, proyek ini bersifat wisata edukasi, masyarakat luar dapet melihat langsung proses pengelolaan sampah dengan memanfaatkan lalat BSF ini. Proyek ini juga bersifat aksi sosial, dengan mempekerjakan para pemulung yang membutuhkan pekerjaan, serta dengan sistem rainharvesting pada proyek, diharapkan dapat membantu masalah air bersih di sekitar tapak. 


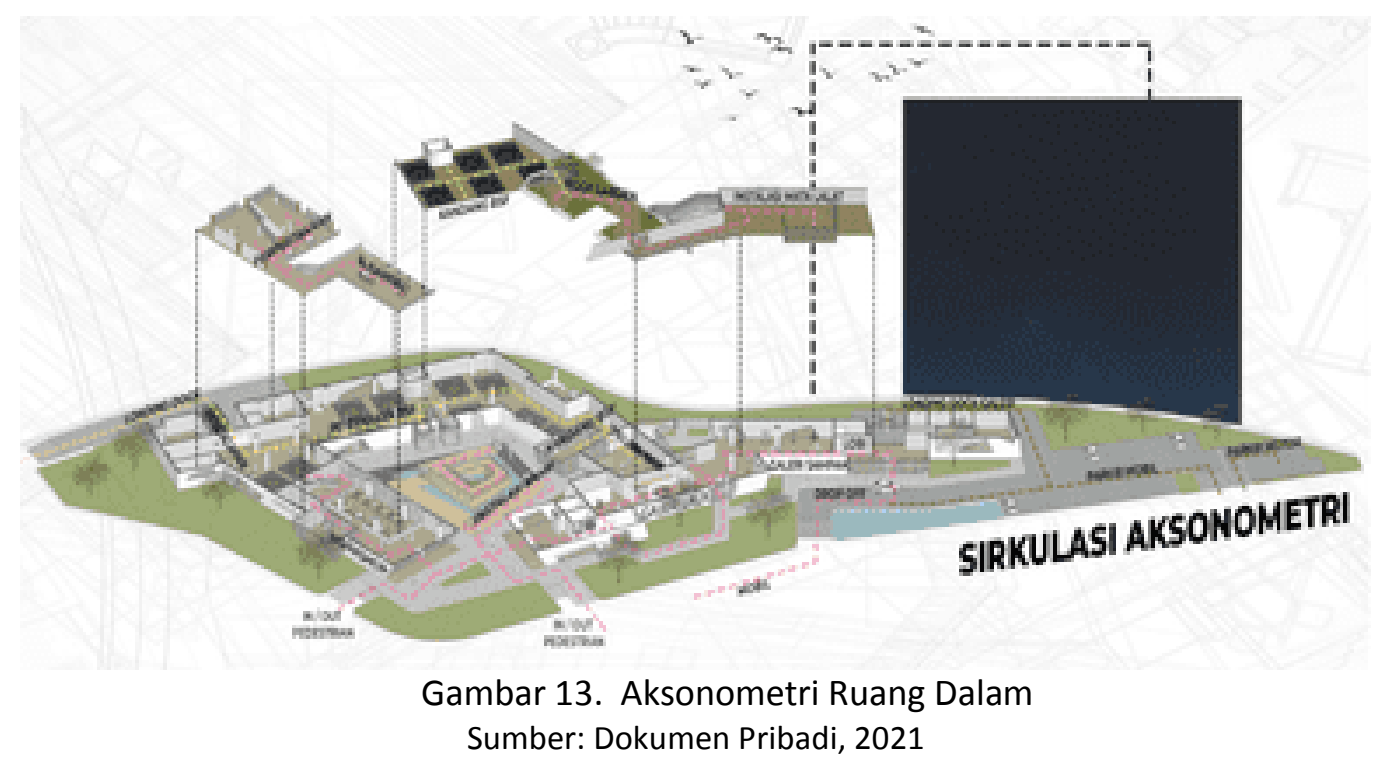

\section{KESIMPULAN DAN SARAN Kesimpulan}

Berdasarkan seluruh hasil Studio Perancangan Akhir ini, bangunan proyek ini berlandaskan aspek-aspek ekologis, dan diharapkan dapat melampaui ekologi. Beberapa hal yang menjadi beyond ecology, antara lain adalah sistem pengolahan sampah dengan lalat BSF sehingga mencakup aspek keberlanjutan, minim emisi, serta kontekstual dengan lingkungan TPST sekitar. Selain itu juga, galeri informasi dan instalasi yang menargetkan ke ranah psikologis masyarakat termasuk sebagai usaha dalam melampaui ekologi. Tidak hanya mengurangi masalah sampah organik, tetapi proyek juga membantu meningkatkan kehidupan para pemulung di TPST sekitar, dengan program seperti workshop sampah dan perpustakaan, sehingga aksi sosial juga dicapai.

\section{Saran}

Masih diperlukan penelitian dan data yang lebih akurat dengan survei langsung ke lokasi agar program dapat lebih realistis dan sistem peternakan dapat berjalan dengan baik.

\section{REFERENSI}

BBC. (2021, 3 1). BBC. Retrieved from BBC: https://www.bbc.com/indonesia/majalah46175945

Beritalima. (2021, 3 1). Beritalima. Retrieved from Beritalima: https://beritalima.com/awalitahun-2020-wamen-lhk-kunjungi-tpst-bantar-gebang/

BPS. (2021, 3 1). Kota Bekasi Dalam Angka 2021. Retrieved from Bekasikota BPS: https://bekasikota.bps.go.id/publication/

Devall, B. (1985). Deep Ecology . Layton, Utha, 8401: Gibbs M. Smith, inc.

Elmira, P. (2021, 3 1). Liputan6. Retrieved from Liputan6: https://www.liputan6.com/lifestyle/read/4069683/kisah-sepasang-pemulung-tertuadi-bantar-gebang

MaterialDistrict. (2021, 3 1). Recycled Park Retrieved plastic waste. Retrieved from materialdistrict: https://materialdistrict.com/article/recycled-park-recycled-retrievedplastic-waste/

Mekano, S. (2011, 3 20). Seeds Of Life. Retrieved from Archdaily: https://www.archdaily.com/120886/seeds-of-life-mekano-studio 
Santi, \& Mahmud, A. T. (2019). Produksi Maggot Lalat Tentara Hitam (Hermetia Illucens) Pada Lama Pemeliharaan Yang Berbeda.

SuaraJakarta. (2021, 3 1). Cerita Lain di Balik Polemik Bantar Gebang: Omzet Ratusan Juta Mengalir dari Sampah. Retrieved from SuaraJakarta: https://suarajakarta.co/news/ekonomi/cerita-lain-di-balik-polemik-bantar-gebangomzet-ratusan-juta-mengalir-dari-sampah/

Sukwika, T., \& Noviana, L. (2020). Status keberlanjutan pengelolaan sampah terpadu di TPSTBantargebang Bekasi: Menggunakan Rapfish dengan R statistik. Status keberlanjutan pengelolaan sampah terpadu di TPST-Bantargebang Bekasi: Menggunakan Rapfish dengan $R$ statistik.

UMM. (2021). Lalat Black Soldier Fly (Hermetia Illucens). Retrieved from Eprints UMM: http://eprints.umm.ac.id/51752/3/BAB\%20II.pdf

Unimus. (2021, 3 1). Definisi dan Siklus Lalat. Retrieved from Unimus: http://repository.unimus.ac.id/992/3/BAB\%20II\%20Lalat.pdf

UNY. $(2021, \quad 3 \quad 1)$ Ekologi. Retrieved from Staff UNY: http://staff.uny.ac.id/sites/default/files/Handout\%20Ekologi_0.pdf 
